\title{
In patients with adult respiratory distress syndrome, initial responders to inhaled nitric oxide did not show better outcome than nonresponders
}

\author{
Hiroshi Hinohara ${ }^{1}$, Yuji Kadoi ${ }^{1}$, Yukitaka Isa ${ }^{1}$, Fumio Kunimoto ${ }^{1}$, Shigeru Ohki ${ }^{2}$, Shigeru Saito ${ }^{3}$, \\ and Fumio Goto ${ }^{3}$ \\ ${ }^{1}$ Department of Intensive Care, Gunma University, Graduate School of Medicine, 3-39-22 Showa-machi, Maebashi 371-8511, Japan \\ ${ }^{2}$ Department of Intensive Care and Second Department of Surgery, Gunma University, Graduate School of Medicine, Maebashi, Japan \\ ${ }^{3}$ Department of Anesthesiology, Gunma University, Graduate School of Medicine, Maebashi, Japan
}

Key words Inhaled nitric oxide $\cdot$ Acute respiratory distress syndrome $\cdot$ Responder $\cdot$ Mortality rate

\section{Introduction}

Inhaled low concentrations of nitric oxide (NO) have been used to treat hypoxemia in patients with acute respiratory distress syndrome (ARDS) [1-5]. Inhaled NO induces selective vasodilation in ventilated lung areas, redistributing blood flow from nonventilated to ventilated regions [2-3,5]. Rossaint et al. [6] reported that in $83 \%$ of 87 patients with ARDS, inhaled NO increased the ratio of arterial $\mathrm{Pa}_{\mathrm{O}_{2}}$ to the fraction of inspired $\mathrm{O} 2\left(\mathrm{~Pa}_{\mathrm{O}_{2}} / \mathrm{FI}_{\mathrm{O}_{2}}\right)$ by $10 \mathrm{mmHg}$. However, they concluded that, although the effects of NO inhalation were beneficial in most patients with severe ARDS, the survival rates of these patients did not differ from those of patients who were not treated with NO.

Inhaled NO cannot always increase arterial oxygenation in patients with ARDS [6-8]. Troncy et al. [2] reviewed factors affecting responsiveness to inhaled NO and found that age, the etiology of ARDS, the pathophysiology and severity of the insult, and ventilation/perfusion mismatching or impaired cardiac reserve might be involved.

We treated 29 patients with inhaled NO to improve arterial oxygenation. This report retrospectively analyzed the factors contributing to improvement of arterial oxygenation with inhaled $\mathrm{NO}$ and assessed if the initial response to inhaled NO would affect the outcome of ARDS patients.

Address correspondence to: Y. Kadoi

Received: December 6, 2002 / Accepted: June 2, 2003

\section{Patients and methods}

We examined data from 29 patients fulfilling the American-European Consensus Conference definition of ARDS who underwent NO inhalation from 1997 to 2001. The University Institutional Review Board approved this therapy for patients with ARDS. Written informed consent was obtained from each patient's family to examine their records. Patients with immunosuppression and advanced malignant disease were excluded.

All patients required mechanical ventilation with a Siemens Servo 300 ventilator (Siemens, Danvers, MA, USA), in a volume-controlled ventilation mode and with a positive end-expiratory pressure (PEEP) of $10-15 \mathrm{cmH}_{2} \mathrm{O}$. We kept peak airway pressures below $50 \mathrm{cmH}_{2} \mathrm{O}$ and applied tidal volumes of $8-10 \mathrm{ml} \cdot \mathrm{kg}^{-1}$. The target oxygenation parameters were $\mathrm{Pa}_{\mathrm{O}_{2}}$ above $60 \mathrm{mmHg}$ and arterial oxygen saturation $\left(\mathrm{Sa}_{\mathrm{O}_{2}}\right)$ above $90 \%$. To achieve sufficient removal of carbon dioxide we adjusted the ventilatory rate to 40 breaths $/ \mathrm{min}$. If hypercapnia developed, we accepted levels of $\mathrm{Pa}_{\mathrm{CO}_{2}}$ below $50 \mathrm{mmHg}$. All patients were sedated with propofol infusions, and muscle relaxation was achieved with vecuronium when necessary.

NO was delivered through the ventilator, using a bleed-in adapter placed in the inspiratory limb of the circuit, just distal to the humidifier. NO was supplied from tanks containing $812 \mathrm{ppm}$, with the remaining gas being nitrogen (Taiyo-Toyo, Kanagawa, Japan). The $\mathrm{NO}$ and $\mathrm{NO}_{2}$ concentrations were continuously monitored using an $\mathrm{NO} / \mathrm{NO}_{2}$ Gas Monitor (TMS-100R; Taiyo-Toyo). Gas samples were withdrawn a short distance proximal to the patient's endotracheal tube, ensuring that a length of $100 \mathrm{~cm}$ was maintained between the central NO instillation and the withdrawal of gas for analysis. The analyzers were regularly calibrated at 0 and 10 ppm NO and 0 and 4 ppm $\mathrm{NO}_{2}$. The exhaled gas was scavenged with an NO nitric oxide scavenger system. 
The inhaled NO concentration was controlled by the patient's attending physician. The suggested protocol was to begin with $5 \mathrm{ppm}$. During the first $12 \mathrm{~h}$, the concentration was generally increased by $5 \mathrm{ppm}$ at 2 to $4-\mathrm{h}$ intervals to obtain a concentration-response relationship at 5, 10, 15, and $20 \mathrm{ppm}$. After the first $12 \mathrm{~h}$, the concentration was adjusted according to the patient's condition and response to the various NO concentrations. All patients were treated with NO inhalation for more than $48 \mathrm{~h}$ in addition to the standard treatment.

The following variables were recorded at baseline, within the first hour of inhaled NO therapy, and regularly thereafter with ongoing inhaled NO treatment: arterial blood gases, $\mathrm{S}_{\mathrm{O}_{2}}$, and mean arterial pressure (MAP). Arterial blood samples were measured by standard techniques. The $\mathrm{Pa}_{\mathrm{O}_{2}} / \mathrm{F}_{\mathrm{O}_{2}}$ value was derived and recorded at baseline and during regular ongoing inhaled NO administration.

The Acute Physiology and Chronic Heath Evaluation (APACHE) II and lung injury scores were calculated using the worst values during the first $12 \mathrm{~h}$ of the intensive care unit (ICU) stay. Organ system failure was defined according to guidelines [7].

Weaning of the inhaled NO was commenced when an $\mathrm{F}_{\mathrm{I}_{2}}$ of $<0.6$ and peak inspiratory pressure (PIP) of $<32 \mathrm{cmH}_{2} \mathrm{O}$ was achieved, while maintaining $\mathrm{Sa}_{\mathrm{O}_{2}}$ at $90 \%$. Thereafter, regular reverse dose-response weaning was conducted every $4-6 \mathrm{~h}$, allowing the dose of inhaled NO to be gradually reduced as clinical improvement progressed.

Patients were placed on a percutaneous cardiopulmonary bypass support (PCPS) system when the target ventilator values $\left(\mathrm{pH}>7.25 ; \mathrm{Sa}_{\mathrm{O}_{2}} \geqq 90 \%\right)$ could not be achieved with conventional ventilation using PIP of $<50 \mathrm{cmH}_{2} \mathrm{O}$ and $\mathrm{F}_{\mathrm{O}_{2}}$ of 1.0. None of the patients in this study received PCPS before the trial of NO inhalation. The inhaled NO therapy was discontinued when patients were placed on PCPS.

ARDS reversal was defined as patients managed for $24 \mathrm{~h}$ at $\mathrm{F}_{\mathrm{O}_{2}}<0.5$ [8]. Discontinuing mechanical ventilation was defined as extubation or pressure support and continuous positive airway pressure, both of $<5 \mathrm{cmH}_{2} \mathrm{O}$ in patients with tracheotomies [9]. To avoid misclassifying patients who had a short duration of mechanical ventilation because of early death as "success", the endpoint used to assess the decrease in mechanical ventilatory support was the number of days that patients remained alive and off mechanical ventilation for at least 2 weeks after the start of inhaled NO therapy.

Six patients died within 14 days after the inhaled NO therapy due to multiple organ failure, so we analyzed 23 patients in this study.

We divided the patients into group A (responders), whose $\mathrm{Pa}_{\mathrm{O}_{2}} / \mathrm{F}_{\mathrm{O}_{2}}$ was increased by $20 \% 48 \mathrm{~h}$ after $\mathrm{NO}$ inhalation compared with baseline values, and group $\mathrm{B}$ (nonresponders), whose $\mathrm{Pa}_{\mathrm{O}_{2}} / \mathrm{F}_{\mathrm{O}_{2}}$ value was unchanged or decreased.

All data values were expressed as means \pm SD. Following the confirmation of equal variance among the groups by the Bartlett test, changes in mean values were compared with the baseline values using two-way repeated measure analysis of variance (ANOVA). Multiple comparisons were made using Scheffe's method, and differences between two groups were analyzed using an unpaired $t$-test or Fisher's $t$-test. Statistical significance was established at $P<0.05$. A Macintosh computer was used to perform all calculations, using SPSS (SPSS, Chicago, IL, USA) and Stat View 5.0 software packages (Abacus Concepts, Berkeley, CA, USA).

\section{Results}

Fourteen patients were classified as group A (responders) and 9 as group B (nonresponders).

Patient characteristics and the data values before NO inhalation (multiple organ failure $[\mathrm{MOF}]$ score, APACHE II score, systemic inflammatory response syndrome [SIRS] score, lung injury score, PCPS use, static respiratory compliance, ventilation days, ARDS duration before inhaled NO therapy ) did not differ significantly between the two groups (Table 1). Mean NO inhalation period, NO concentration, total ICU stay, total ARDS duration, ventilation days, and mortality rates also did not differ significantly between the groups.

\section{Discussion}

The present study could not identify predictable variables for improving arterial oxygenation by NO inhalation and did not demonstrate a better outcome in patients with ARDS who were responders to NO inhalation.

Whether inhaled NO helps to improve arterial oxygenation in patients with ARDS remains controversial [2-3,8]. Troncy et al. [4] reported that, after the first day of NO inhalation therapy, no further beneficial effect of NO inhalation was evident and that the 30-day mortality rates were similar in controls and in those who inhaled NO. They concluded that NO inhalation might improve gas exchange but that it does not affect mortality. Mclntyre et al. [5] reported that NO inhalation should not be recommended for all patients with ARDS. Michael et al. [8] compared the effects of conventional therapy and of inhaled NO on oxygenation, and found that inhaled NO therapy did not lead to a sustained improvement in oxygenation in patients with 
Table 1. Patient characteristics and the variables during NO inhalation

\begin{tabular}{|c|c|c|c|}
\hline & Group A (Responders) & Group B (nonresponders) & $P$ value \\
\hline \multicolumn{4}{|l|}{ Patient characteristics } \\
\hline Number & 14 & 9 & \\
\hline Age (years) & $59 \pm 15$ & $63 \pm 9$ & 0.50 \\
\hline Height $(\mathrm{cm})$ & $160 \pm 9$ & $157 \pm 6$ & 0.35 \\
\hline Weight $(\mathrm{kg})$ & $61.0 \pm 17.7$ & $56.2 \pm 13.1$ & 0.51 \\
\hline Male/Female & $9 / 5$ & $5 / 4$ & 0.67 \\
\hline \multicolumn{4}{|l|}{ Data before NO inhalation } \\
\hline MOF score & $5.5 \pm 1.9$ & $7.5 \pm 3.7$ & 0.10 \\
\hline APACHE II score & $18.9 \pm 4.0$ & $20.6 \pm 4.3$ & 0.34 \\
\hline SIRS score & $2.3 \pm 0.6$ & $2.1 \pm 1.0$ & 0.64 \\
\hline Lung injury score & $2.9 \pm 0.6$ & $3.1 \pm 0.5$ & 0.46 \\
\hline PCPS use & $4 / 41(29 \%)$ & $4 / 9(44 \%)$ & 0.43 \\
\hline \multicolumn{4}{|l|}{ Static respiratory compliance before } \\
\hline iNO therapy $\left(\mathrm{ml} / \mathrm{cmH}_{2} \mathrm{O}\right)$ & $30.5 \pm 27.0$ & $32.3 \pm 22.4$ & 0.87 \\
\hline ARDS duration before iNO therapy (days) & $3.1 \pm 3.2$ & $3.8 \pm 3.5$ & 0.68 \\
\hline \multicolumn{4}{|l|}{ Etiology of ARDS } \\
\hline Sepsis & 2 & 1 & \\
\hline Aspiration pneumonia & 1 & 0 & \\
\hline Pneumonia & 8 & 3 & \\
\hline SLE & 0 & 2 & \\
\hline Postoperative MOF & 3 & 3 & \\
\hline \multicolumn{4}{|l|}{ Data after NO inhalation } \\
\hline NO inhalation period (days) & $5.9 \pm 3.0$ & $16.0 \pm 18.9$ & 0.06 \\
\hline Mean NO concentration (ppm) & $4.5 \pm 2.2$ & $6.2 \pm 4.5$ & 0.30 \\
\hline ICU stay (days) & $39.4 \pm 28.6$ & $36.6 \pm 18.4$ & 0.81 \\
\hline Total ARDS duration (days) & $25.2 \pm 18.4$ & $28.5 \pm 20.4$ & 0.70 \\
\hline Ventilation (days) & $31.4 \pm 21.7$ & $35.6 \pm 17.9$ & 0.65 \\
\hline Mortality & $6 / 14(43 \%)$ & $6 / 9(67 \%)$ & 0.26 \\
\hline
\end{tabular}

Values are means \pm SD.

NO, nitric oxide; MOF, multiple organ failure; SIRS score, systemic inflammatory response syndrome score; APACHE II, acute Physiology and Chronic Health Evaluation II; PCPS, percutaneous cardiopulmonary bypass support; iNO, inhaled NO; SLE, systemic lupus erythematosus; ARDS, adult respiratory distress syndrome; ICU, intensive care unit

ARDS. However, they found that the patients improved to the point where they could be managed with a persistent decrease in $\mathrm{F}_{\mathrm{O}_{2}}$ by 0.15 within $72 \mathrm{~h}$, and that a small improvement in respiratory status, as indicated by a persistent decrease in $\mathrm{F}_{\mathrm{O}_{2}}$, was a very hopeful prognostic sign for ARDS patients. In contrast, Goldman et al. [10] reported that a greater early response to inhaled NO appeared to be associated with improved outcome in acute hypoxemic respiratory failure in children. These contradictory results could be attributable to differences in study subjects. The causes of ARDS in adults differ from those in children. Another possibility is that the death of patients with ARDS might not always be due to respiratory failure, so to evaluate the endpoint of inhaled NO in terms of the resolution of ARDS or in terms of mortality is impossible.

We did not find predictable variables for improving arterial oxygenation after NO inhalation therapy in patients with ARDS. Michael et al. [8] reported that the ARDS duration within the 3 days before inhaled NO therapy and static respiratory compliance of $<19 \mathrm{~cm} /$ $\mathrm{cmH}_{2} \mathrm{O}$ were associated with the ability of inhaled $\mathrm{NO}$ to decrease $\mathrm{F}_{\mathrm{O}_{2}}$ over the next $72 \mathrm{~h}$. However, no significant differences in ARDS duration before inhaled NO therapy or in static respiratory compliance were found between the two groups in our study. Troncy et al. [4] surmised that the use of different criteria for improvement in arterial oxygenation could lead to contradictory results.

Many reports have described the effects of inhaled NO therapy on arterial oxygenation in patients with ARDS [1-6]. Rossaint et al. [1] originally examined the effect of 5 to $20 \mathrm{ppm}$ of inhaled NO for 3 to 53 days on arterial oxygenation in ten patients with ARDS. They found that NO inhalation by patients with severe ARDS reduced the pulmonary-artery pressure and increased arterial oxygenation by improving the matching of ventilation with perfusion, without producing systemic vasodilation. They reported in a subsequent study [6] that NO inhalation was beneficial to most patients with severe ARDS. Although the mortality rate might 
not have been improved in that recent study, improved oxygenation with inhaled NO may have had a beneficial effect on ARDS.

In conclusion, our analysis of 23 ARDS patients treated with inhaled NO revealed no specific contributing factors affecting responsiveness to inhaled NO and no differences in mortality rates between responders and nonresponders to the therapy.

\section{References}

1. Rossaint R, Falke KJ, Lopez F, Slama K, Pison U, Zapol WM (1993) Inhaled nitric oxide for the acute respiratory distress syndrome. New Engl J Med 328:399-405

2. Troncy E, Francoeur M, Blaise G (1997) Inhaled nitric oxide: clinical applications, indications, and toxicology. Can J Anesth 44:973-988

3. Kopp R, Kuhlen R, Max M, Rossaint R (2002) Evidence-based medicine in the therapy of the acute respiratory distress syndrome. Intensive Care Med 28:244-255

4. Troncy E, Collet JP, Shapiro S, Guimond JG, Blair L, Ducruet T, Francceur M, Charbonneau M, Blaise G (1998) Inhaled nitric oxide in acute respiratory distress syndrome. Am J Respir Crit Care Med 157:1483-1488

5. Mclntyre RC, Pulido EJ, Bensard DD, Shames BD, Abraham E (2000) Thirty years of clinical trial in acute respiratory distress syndrome. Crit Care Med 28:3314-3331

6. Rossaint R, Gerlach H, Ruhnke HS, Pappert D, Lewandowski K, Steudel W, Falke K (1995) Efficacy of inhaled nitric oxide in patients with severe ARDS. Chest 107:1107-1115

7. Bernard GR (1998) Quantification of organ dysfunction: seeking standardization. Crit Care Med 26:1767-1768

8. Michael JR, Barton RC, Saffle JR, Mone M, Markewitz BA, Hillier K, Elstad MR, Campbell EJ, Troyer BE, Whatley RE, Liou TG, Samuelson WM, Carveth HJ, Hinson DM, Morris SE, Davis BL, Day RW (1998) Inhaled nitric oxide versus conventional therapy. Am J Respir Crit Care Med 157:1372-1380

9. Dellinger RP, Zimmerman JL, Taylor RW, Straube RC, Hauser DL, Criner GJ, Davis K, Hyeres TM, Papadakos P (1998) Effects of inhaled nitric oxide in patients with acute respiratory distress syndrome: results of a randomized phase II trial. Crit Care Med 26:15-23

10. Goldman AP, Tasker RC, Hosiason S, Henrichsen T, Macrae DJ (1997) Early response to inhaled nitric oxide and its relationship to outcome in children with severe hypoxemic respiratory failure. Chest 112:752-758 